\title{
Evaluation of the nasal mucociliary transport rate by rhinoscintigraphy before and after surgery in patients with deviated nasal septum
}

\author{
Cahit Polat $\cdot$ Zeki Dostbil
}

Received: 30 June 2009/ Accepted: 24 September 2009/Published online: 9 October 2009

(c) The Author(s) 2009. This article is published with open access at Springerlink.com

\begin{abstract}
In this study, we have investigated the effect of nasal septal deviation (NSD) on nasal mucociliary activity and how does a septoplasty operation affecs the nasal mucociliary transport rate in the first and third months during the post-operative period. Twenty-two patients who were diagnosed with NSD and 22 healthy controls were studied using rhinoscintigraphy with Tc-99m-macroaggregated albumin (Tc-99m-MAA). On each case, the nasal mucociliary transport rate (NMTR) was measured preoperatively only on five cases, on the first and third months of post-operative period. The NMTRs of patients with a deviated septum were significantly lower than the NMTRs of the healthy controls on both the convex and concave sides. Significant improvement was observed in the first post-operative month. On the concave and convex sides, the average postop third month post-operative NMTR value was higher than the first month post-operative NMTR values. It was concluded that the septoplasty operation improves reduced NMTRs after surgery. The effect of nasal surgery on nasal mucociliary activity may be more accurately evaluated in the third month than the first month of post-operative period.
\end{abstract}

Keywords Nasal septum - Septal deviation . Septoplasty $\cdot$ Mucociliary clearance $\cdot$ Rhinoscintigraphy

\section{Polat}

Department of Otorhinolaryngology-Head and Neck Surgery,

Elazig Research and Training Hospital, Elazig, Turkey

\section{Z. Dostbil ( $\square)$}

Department of Nuclear Medicine,

Dicle University Medical Faculty, Diyarbakir, Turkey

e-mail: zekidostbil@yahoo.com

\section{Introduction}

The nasal septum is an important structure which has a supportive role and affects the intranasal airflow pattern [1]. The nasal septum contributes to the temperature and moisture of the inhaled air to make it more suitable for the body and filtrates air from particles by its ciliated mucosa $[2,3]$. Mucociliary transport is the physiological process in which the mucus layer on ciliated cells is moved. Particles are transported toward the nasopharynx by means of nasal mucociliary activity (MCA). This MCA is a first line of defense mechanism for physical and biological insults in the nasal fossa, paranasal sinuses and lower respiratory tract. Nasal MCA depends on the number of cilia and the beat frequency, their coordinated movements, the amount of nasal fluid and viscoelastic properties [4].

Many in vivo and in vitro techniques have been used for the measurement of MCA [5, 6]. In vitro techniques such as stroboscopy, photon-electron techniques and phase contrast microscopy make the measurement via determination of the ciliary beat frequency. However, they are too expensive and not suitable for routine use. In vivo techniques such as saccharine, charcoal and radionuclides using rhinoscintigraphy have been also used by many researchers $[4,7]$. These methods can be performed easily and not too expensive. Rhinoscintigraphy is an objective and sensitive method used in the follow-up of nasal and paranasal surgery, and in determining the effectiveness of drug therapy for various nasal pathologies [7, 8]. In rhinoscintigraphy, very small dosage of Tc-99m is used. This dosage gives only negligible gamma radiation exposure to the patients.

In many studies it has been shown that in addition to a deviated septum causing nasal obstruction, impairment of intranasal airflow, and turbulence [9, 10], a deviated septum negatively affects nasal MCA, likely due to ciliary 
loss, increased inflammation, and a decreased density in glandular acini [11]. Septoplasty operation has been performed in the treatment of NSD [12, 13].

In this study, we aimed to investigate the effect of surgery on MCA on the convex (deviated side) and concave sides (contralateral side) in the first and third months of post-operative period in patients with a deviated nasal septum.

\section{Materials and methods}

For the patient group, 22 subjects between the age of 13-48 years [13 men and 9 women, $21.09 \pm 8.33$ years (mean $+\mathrm{SD})]$ with complaints of chronic nasal obstruction and who were diagnosed with NSD by means of anterior rhinoscopy and an endoscopic nasal examination by an 'ear nose and throat specialist', and 22 healthy subjects between the age of 14-48 years (11 men and 11 women, $24.5 \pm 9.51$ years) for the control group were included in this study between April and October 2008.

Before each test; detailed ear, nose, throat, head, and neck examinations were performed in all cases. Patients with allergic rhinitis, chronic sinusitis, concha bullosa, nasal polyposis, turbinate hypertrophy, acute upper respiratory tract infection, rhinosinusitis within the last 2 weeks, any systemic illnesses, lactation, and who were smoking, had any drug therapy within the last week and were pregnant were excluded from the study.

In the patient group, rhinoscintigraphy was performed on both the convex and concave sides before the septoplasty, in the first month after surgery and, in some patients with less improvement in MCA at the first month measurement, at the post-operative third month, and at any time on both nasal cavities with 2-day intervals in the control group. In this test, one droplet $(\sim 50 \mu \mathrm{Ci})$ of $\mathrm{Tc}-99 \mathrm{~m}$ macroaggregated albumin (Tc-99m-MAA) (particle size ranged between 10 and $150 \mu \mathrm{m}$ ) was dripped on the floor of the nasal meatus approximately $1 \mathrm{~cm}$ behind the anterior end of the inferior turbinate with a $27 \mathrm{~g}$ syringe. In order to prevent application and interpretation diversity, all tests were performed by the same staff. The room temperature was stabilized at $21^{\circ} \mathrm{C}$. In the supine position, images were obtained using a GE Infinia gamma camera system with a LEHR collimator. Detectors were set laterally. Before the test, each patient was informed about the test procedure and their written consent was obtained. Thirty-second dynamic images were obtained during $20 \mathrm{~min}$. After the subjects were removed from the table, a plate on which there were two radioactive point sources apart $10 \mathrm{~cm}$ from each other was placed on the table where the patients put their heads. Then, a 30-s additional static image was taken. After the test was completed, the images were processed.
The distance between the point where the radiopharmaceutical was dripped and the point where the particles reached the nasal cavity was measured on a straight line with a system computer. This value was corrected with respect to the $10 \mathrm{~cm}$ point image. Then, to determine the NMTR in $\mathrm{mm} / \mathrm{min}$, this length was divided by the time which had elapsed.

For statistical analyses, the 't-test for independent groups' was used in comparison of the control and patient groups, and the right and left side data. The ' $t$-test for paired groups' was used for the data of the patient group for comparison. The first and third months post-operative data were compared by an ANOVA test, and $P$ value $<0.05$ was accepted as statistically significant. Before starting the study, we obtained approval from the Elazig Training and Research Hospital Ethics Committee.

\section{Results}

The average NMTR of the convex side before surgery was $6.5 \pm 3.04 \mathrm{~mm} / \mathrm{min}$ (mean $\pm \mathrm{SD}$ ) and that of the concave side was $5.38 \pm 2.94 \mathrm{~mm} / \mathrm{min}$ (Table 1). There was no statistically significant difference between the two sides $(P=0.222)$. In the control group, we found that the average NMTR of the left side was $8.15 \pm$ $2.46 \mathrm{~mm} / \mathrm{min}$, the average NMTR of the right side was $8.5 \pm 2.61 \mathrm{~mm} / \mathrm{min}$, and the average NMTR of the right and left sides was $8.32 \pm 2.44 \mathrm{~mm} / \mathrm{min}$ (Table 2). There was no significant difference between the right and left side values of the control group $(P=0.651)$. In comparison, we found that the pre-operative NMTR values of the convex and concave sides were significantly lower than the healthy controls $(P=0.035$ and $P<0.001$, respectively). In the first month of the post-operative period, the average NMTR of the convex side was $8.64 \pm 2.8 \mathrm{~mm} / \mathrm{min}$ and the average NMTR of the concave side was $6.85 \pm 2.76 \mathrm{~mm} / \mathrm{min}$ (Table 1). When the pre- and post-operative first month values of the convex and concave sides were compared, we found that there were significant increases in both the convex and concave sides $(P<0.001$ and $P<0.001$, respectively). There was no significant difference between the first month post-operative NMTR values of both sides and that of the control group when compared $(P=0.690$ and $P=0.069$, respectively).

In five cases in whom we performed the test in the first and third months post-operatively, the average NMTRs of the convex side were $4.52 \pm 1.56 \mathrm{~mm} / \mathrm{min}$ in the preoperative period, $5.79 \pm 1.95 \mathrm{~mm} / \mathrm{min}$ in the first month post-operatively, and $8.94 \pm 1.94 \mathrm{~mm} / \mathrm{min}$ in the third month post-operatively; whereas, the average NMTRs of the concave side were $3.07 \pm 2.38 \mathrm{~mm} / \mathrm{min}$ in the preoperative period, $3.49 \pm 2.23 \mathrm{~mm} / \mathrm{min}$ in the first month 
Table 1 Nasal mucociliary transport rates of patients with a deviated nasal septum

\begin{tabular}{|c|c|c|c|c|c|c|c|c|}
\hline \multirow[t]{3}{*}{ Case no } & \multirow[t]{3}{*}{ Age (years) } & \multirow[t]{3}{*}{ Gender } & \multicolumn{6}{|c|}{ NMTR $(\mathrm{mm} / \mathrm{min})$} \\
\hline & & & \multicolumn{2}{|l|}{ Pre-op } & \multicolumn{2}{|c|}{ Post-op first month } & \multicolumn{2}{|c|}{ Post-op third month } \\
\hline & & & Convex & Concave & Convex & Concave & Convex & Concave \\
\hline 1 & 17 & $\mathrm{~F}$ & 6.41 & 3.42 & 6.84 & 3.62 & 10.87 & 7.14 \\
\hline 2 & 19 & M & 11.36 & 6.68 & 13.52 & 8.88 & & \\
\hline 3 & 30 & M & 5.54 & 2.73 & 12.33 & 5.88 & & \\
\hline 4 & 28 & M & 3.85 & 2.28 & 8.6 & 6.83 & & \\
\hline 5 & 17 & M & 4.56 & 2.9 & 7.75 & 5.6 & & \\
\hline 6 & 18 & M & 6.78 & 8.36 & 7.8 & 8.9 & & \\
\hline 7 & 15 & M & 6.95 & 8.12 & 7.18 & 9.11 & & \\
\hline 8 & 34 & $\mathrm{~F}$ & 1.6 & 1.29 & 2.36 & 1.48 & 6.74 & 7.04 \\
\hline 9 & 18 & M & 6.55 & 4.45 & 10.84 & 6.72 & & \\
\hline 10 & 17 & M & 5.05 & 3.55 & 6.54 & 4.1 & 10.5 & 8.34 \\
\hline 11 & 17 & $\mathrm{~F}$ & 4.51 & 5.82 & 9.65 & 6.8 & & \\
\hline 12 & 14 & $\mathrm{~F}$ & 11.4 & 12.86 & 11.65 & 12.9 & & \\
\hline 13 & 18 & M & 10.71 & 6.65 & 11.73 & 7.7 & & \\
\hline 14 & 18 & $\mathrm{~F}$ & 1.41 & 4.09 & 4.8 & 8.98 & & \\
\hline 15 & 13 & $\mathrm{~F}$ & 10.14 & 2.71 & 10.62 & 3.57 & & \\
\hline 16 & 22 & $\mathrm{~F}$ & 10.72 & 6.97 & 12.44 & 7.56 & & \\
\hline 17 & 48 & M & 3.96 & 0.5 & 6.1 & 1.43 & 7.37 & 5.44 \\
\hline 18 & 16 & $\mathrm{~F}$ & 3.76 & 7.97 & 5.83 & 8.56 & & \\
\hline 19 & 17 & $\mathrm{~F}$ & 5.62 & 6.63 & 7.13 & 6.85 & 9.25 & 8.15 \\
\hline 20 & 17 & M & 7.19 & 8.15 & 8.27 & 9.44 & & \\
\hline 21 & 32 & M & 4.95 & 4.38 & 7.88 & 6.75 & & \\
\hline 22 & 19 & M & 10.06 & 7.94 & 10.28 & 9.13 & & \\
\hline Mean $\pm \mathrm{SD}$ & $21.09 \pm 8.33$ & M: 13, F: 9 & $6.50 \pm 3.04$ & $5.38 \pm 2.94$ & $8.64 \pm 2.8$ & $6.85 \pm 2.76$ & & \\
\hline
\end{tabular}

NMTR Nasal mucociliary transport rate, convex deviated side, concave contralateral side

post-operatively, and $7.22 \pm 1.15 \mathrm{~mm} / \mathrm{min}$ in the third month post-operatively (Table 3). When the first and third months post-operative NMTRs of the convex and concave sides were compared, some improvement was found on each side (Figs. 1, 2, 3).

\section{Discussion}

Mucociliary transport is an important defense mechanism against physical and biological insults in the nasal fossa and paranasal sinuses. Foreign particles and microorganisms in the air inspired are filtrated by means of the MCA $[4,5]$ and incidence of rhinosinusitis is increased in cases when the MCA is impaired [4, 14, 15]. NSD negatively affects the MCA, likely due to loss of cilia, increased inflammation, and decreased density of glandular acini [11]. Following a septoplasty, impairment of the MCA is improved with time $[8,9,16]$.

In this study, some patients with deviated septum had left deviation and some had right deviation. In the control group, we did not find any significant difference between the NMTRs of the right and left nasal cavities $(P=0.651)$, so we compared the NMTR values of the patients with the average of the left and right side NMTRs of the control group. The NMTRs of patients with deviated septum were significantly lower than the healthy controls on both the convex and concave sides. In the first month post-operative measurements, we observed significantly higher NMTRs on both sides. Before the post-operative period tests, all of the patient's noses were examined endoscopically. In all cases, we observed improvement and there was no need for any revision procedures. In the cases in which the first month post-operative NMTR values showed little improvement, third month post-operative measurements were performed to determine if the improvement continued. Unfotunately, we could perform the test only in five cases for various reasons. We found that on the concave and convex sides, the average third month post-operative NMTR value was higher than the first month post-operative NMTR values.

We did not consider age and gender in choosing subjects for study since the age, gender, posture, and dripping point 
Table 2 Control group

\begin{tabular}{|c|c|c|c|c|c|c|}
\hline \multirow{2}{*}{ Table 2 Control group } & \multirow[t]{2}{*}{ No } & \multirow[t]{2}{*}{ Age (years) } & \multirow[t]{2}{*}{ Gender } & \multicolumn{3}{|c|}{ NMTR (mm/min) } \\
\hline & & & & Left & Right & Mean \\
\hline & 1 & 15 & $\mathrm{~F}$ & 10.53 & 9.42 & 9.97 \\
\hline & 2 & 47 & M & 6.9 & 5.25 & 6.07 \\
\hline & 3 & 14 & M & 10.3 & 10.7 & 10.5 \\
\hline & 4 & 33 & M & 9.63 & 7.65 & 8.64 \\
\hline & 5 & 28 & $\mathrm{~F}$ & 6.92 & 7.38 & 7.15 \\
\hline & 6 & 28 & M & 11.85 & 10.77 & 11.31 \\
\hline & 7 & 21 & $\mathrm{~F}$ & 7.4 & 10.95 & 9.17 \\
\hline & 8 & 19 & $\mathrm{~F}$ & 13.15 & 13.37 & 13.26 \\
\hline & 9 & 25 & M & 6.65 & 6.35 & 6.5 \\
\hline & 10 & 14 & $\mathrm{~F}$ & 5.58 & 6.73 & 6.15 \\
\hline & 11 & 29 & M & 8.56 & 9.17 & 8.86 \\
\hline & 12 & 16 & M & 10.48 & 11.46 & 10.97 \\
\hline & 13 & 19 & $\mathrm{~F}$ & 5.77 & 8.78 & 7.27 \\
\hline & 14 & 20 & $\mathrm{~F}$ & 7.46 & 8.14 & 7.8 \\
\hline & 15 & 18 & $\mathrm{~F}$ & 5.27 & 5.54 & 5.4 \\
\hline & 16 & 22 & M & 7.94 & 7.55 & 7.74 \\
\hline & 17 & 17 & M & 8.63 & 8.14 & 8.38 \\
\hline & 18 & 26 & $\mathrm{~F}$ & 2.47 & 2.63 & 2.55 \\
\hline & 19 & 35 & $\mathrm{~F}$ & 5.93 & 5.91 & 5.92 \\
\hline & 20 & 19 & M & 9.17 & 8.82 & 8.99 \\
\hline & 21 & 48 & $\mathrm{~F}$ & 8.22 & 9.15 & 8.68 \\
\hline & 22 & 26 & M & 10.54 & 13.17 & 11.85 \\
\hline $\begin{array}{l}\text { NMTR: Nasal mucociliary } \\
\text { transport rate }\end{array}$ & Mean \pm SD & $24.5 \pm 9.51$ & M: 11, F: 11 & $8.15 \pm 2.46$ & $8.5 \pm 2.61$ & $8.32 \pm 2.44$ \\
\hline
\end{tabular}

NMTR: Nasal mucociliary transport rate

Table 3 Patients in whom NMTRs were measured in the first and third months post-operatively

\begin{tabular}{|c|c|c|c|c|c|c|}
\hline \multirow[t]{3}{*}{ No. } & \multicolumn{6}{|c|}{ NMTR $(\mathrm{mm} / \mathrm{min})$} \\
\hline & \multicolumn{3}{|l|}{ Convex } & \multicolumn{3}{|l|}{ Concave } \\
\hline & Pre-op & Post-op first month & Post-op third month & Pre-op & Post-op first month & Post-op third month \\
\hline 1 & 6.41 & 6.84 & 10.87 & 3.42 & 3.62 & 7.14 \\
\hline 2 & 1.6 & 2.36 & 6.74 & 1.29 & 1.48 & 7.04 \\
\hline 3 & 5.05 & 6.54 & 10.5 & 3.55 & 4.1 & 8.34 \\
\hline 4 & 3.96 & 6.1 & 7.37 & 0.5 & 1.43 & 5.44 \\
\hline 5 & 5.62 & 7.13 & 9.25 & 6.63 & 6.85 & 8.15 \\
\hline Mean $\pm \mathrm{SD}$ & $4.52 \pm 1.56$ & $5.79 \pm 1.95$ & $8.94 \pm 1.94$ & $3.07 \pm 2.38$ & $3.49 \pm 2.23$ & $7.22 \pm 1.15$ \\
\hline
\end{tabular}

NMTR Nasal mucociliary transport rate

in the nasal cavity have been shown not to affect the accuracy of rhinoscintigraphy $[17,18]$. Patients who have any situation that affected or potentially affected the accuracy of rhinoscintigraphy, such as systemic illnesses, drug usage, recent upper respiratory tract infection, or smoking, were excluded from the study $[19,20]$.

There are various techniques to evaluate ciliary activity in the nasal mucosa. Techniques, such as stroboscopy, roentgenography, and photoelectron techniques, can evaluate ciliary activity and ciliary beat frequency. However, such techniques are expensive and not suitable for routine use [7]. Most often, the tests used to measure MCA are rhinoscintigraphy and the saccharin test. The latter is very simple and inexpensive. In this test, a saccharin solution is dripped in the nasal cavity. This substance is carried to the nasopharynx and causes the patient to sense a taste of sugar. The time interval between the dripping process and sensing the sugar taste is noted. The main disadvantages of this test are that the NMTR cannot be measured and rely on the patient's sense of taste. Rhinoscintigraphy can supply 
Fig. 1 Nasal mocociliary transport rate of patient and control group subjects
Fig. 2 Images of a patient with a deviated nasal septum are shown above. On the left image, the NMTR was measured as $4.56 \mathrm{~mm} / \mathrm{min}$ before the septoplasty and on the right image in the first month postoperatively, a significant improvement in NMTR $(7.75 \mathrm{~mm} / \mathrm{min})$ of same patient can be seen

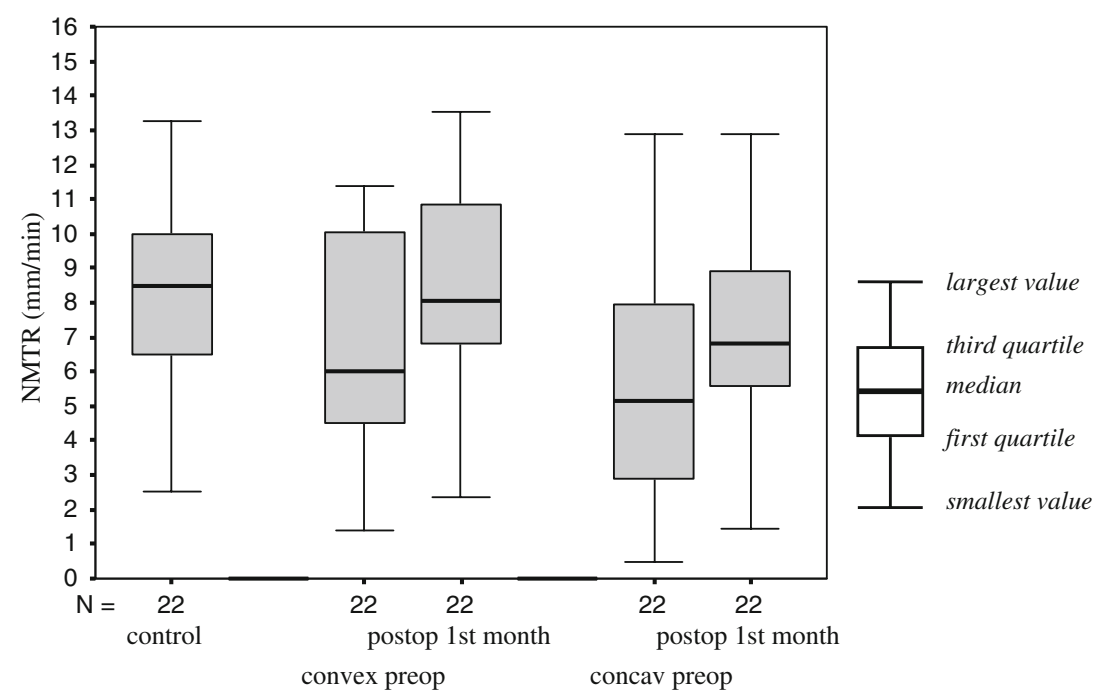

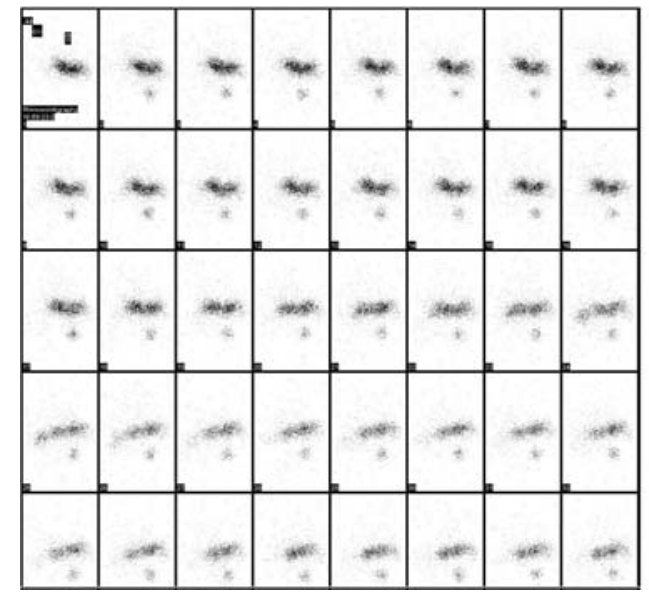

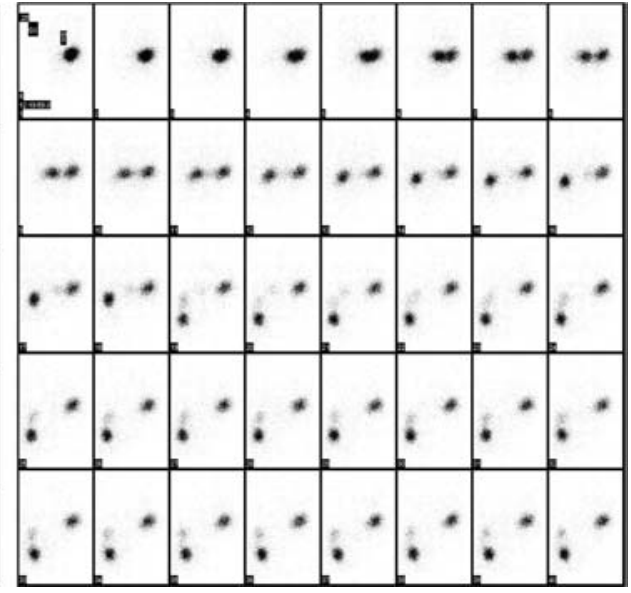

objective and detailed information that allows quantitative analyses [16]. For this test, various radiopharmaceuticals (colloid solution, resin particles, and albumin particles) have been suggested. Currently, most researchers use Tc99m-MAA for rhinoscintigraphy [7]. Rhinoscintigraphy has been shown to be a reliable, easily reproducible, and harmless method, so it may be used for follow-up examinations in patients who have had surgery of the nose and paranasal sinuses, and for drug therapy for rhinopathic conditions [7]. Thus, we also preferred Tc-99m-MAA for rhinoscintigraphy in this study.

In review of studies using rhinoscintigraphy in the most recent 14 years $[5,7,9,17,21-23]$, we have seen that the average NMTRs of healthy individuals range between 4.48 and $17.94 \mathrm{~mm} / \mathrm{min}$ (mean $8.92 \mathrm{~mm} / \mathrm{min}$ ). In all of these studies, individual NMTRs range between 1.2 and $28.7 \mathrm{~mm} / \mathrm{min}$. In our study, we obtained NMTRs ranging between 2.47 and $13.37 \mathrm{~mm} / \mathrm{min}$ (mean $8.32 \mathrm{~mm} / \mathrm{min}$ ) in the healthy control group subjects. Our findings are in agreement with the literature. These different NMTR values found in various studies may be due to different environments, seasons, and non-standardization of test techniques.

Ulusoy et al. [9] studied 20 patients with nasal septal deviation and 20 healthy controls using Tc-99m-MAA rhinoscintigraphy. They found NMTRs of $17.94 \pm$ $2.89 \mathrm{~mm} / \mathrm{min}$ in the control group, $10.78 \pm 3.53 \mathrm{~mm} / \mathrm{min}$ on the convex side, and $10.24 \pm 3.96 \mathrm{~mm} / \mathrm{min}$ on the concave side in the patient group in the first month postoperatively. Our findings in this study were considerably lower $(8.32 \pm 2.44,6.5 \pm 3.04$, and $5.38 \pm 2.94 \mathrm{~mm} / \mathrm{min}$, respectively), although the same technique was used. This difference may be attributed to differences in computer analyses and the factors mentioned above. Juhani et al. [5] studied the asymmetry in the nasal mucociliary transport rate in 16 healthy subjects using rhinoscintigraphy and found a statistically significant difference $(P<0.001)$ between the right and left NMTRs. Thus, they concluded that there is asymmetry in the nasal mucociliary transport rates in the right and left nasal cavities of healthy individuals. We did not find any significant differences $(P=0.651)$ between the right and left side transport rates, 


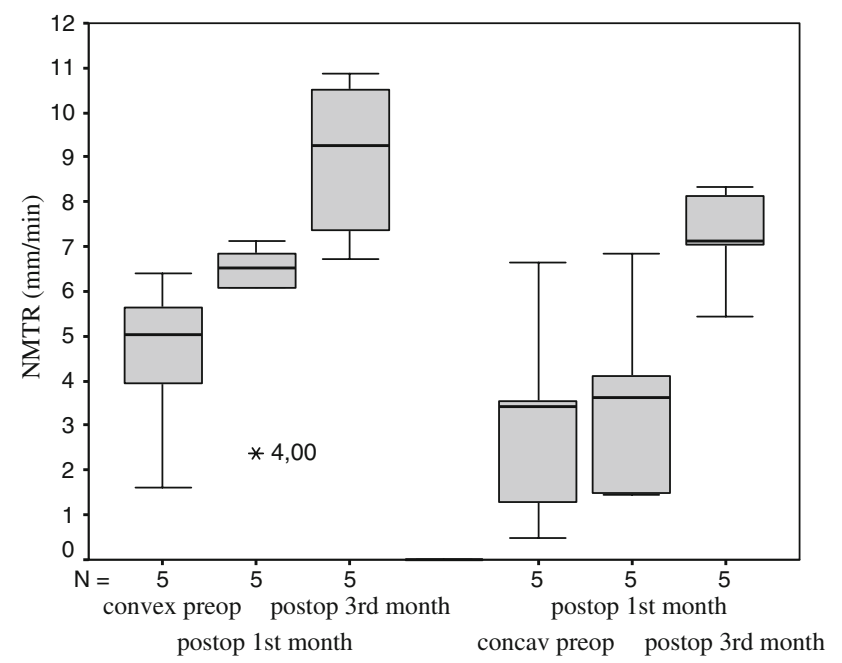

Fig. 3 Nasal mucociliary transport rate of patients in whom the test was performed in the first and third months post-operatively

consistent with Ulusoy et al. [9]. The different findings of Juhani et al. [5] may be the result of not using exactly same criteria as ours in choosing the healthy subjects in their study. Based on our study findings, we suggest that there is no asymmetry in the nasal mucociliary transport rates in the right and left nasal cavities of healthy individuals.

Regarding the effect of septoplasty on nasal MCA, some studies have repeated the measurement of NMTR in the first month post-operatively [9] and others have repeated the measurement of NMTE in the second month postoperatively [8]. In all of these studies, it has been shown that surgical correction of the nasal septum significantly improves the impaired MCA [8, 9, 16]. Ohashi et al. [24] have reported that complete recovery of the nasal mucosa after trauma has been suggested to occur after a postoperative period of 5 days if the basal cells and basement membrane are intact. When the entire nasal mucosa was injured mechanically, regenerative stratified epithelium covered the defect in 1 week, new ciliated cells appeared in 3 weeks, and complete regeneration was observed at 6 weeks. In our study, the NMTRs improved very little at the first month post-operatively. When we performed the test in five such cases at the third month post-operatively, we observed that the NMTRs were higher than before on each side. This finding suggested that repeating the test at the first month post-operatively in patients with nasal septal deviation may lead to false results in some cases.

Our study showed that NSD impairs nasal mucociliary activity. Septoplasty improves reduced NMTRs after surgery. The effect of nasal surgery on nasal mucociliary activity may be evaluated more accurately at the third month than the first month of post-operative period. The number of patients who were tested by rhinoscintigraphy in both first and third months post-operatively was five, which is insufficient. To understand if there is real statistically significant difference between NMTRs values of post-op first and third months, new studies should be planned on this issue with greater patient number.

Conflict of interest statement The authors declare that they have no financial relationship with any organization related to the research and no conflict of interest.

Open Access This article is distributed under the terms of the Creative Commons Attribution Noncommercial License which permits any noncommercial use, distribution, and reproduction in any medium, provided the original author(s) and source are credited.

\section{References}

1. William EW, Robert CK (2006) Sinonasal anatomy, function and evaluation. In: Bailey BJ, Johnson JT, Newlands SD (eds) Head and neck surgery-otolaryngology, 4th edn. Lippincott Williams \& Wilkins, Philadelphia, pp 307-318

2. Simmen D, Scherrer JL, Moe K, Heinz B (1999) A dynamic and direct visualization model for the study of nasal airflow. Arch Otolaryngol Head Neck Surg 125:1015-1021

3. Toremalm NG (1985) Aerodynamics and mucociliary function of upper airways. Eur J Respir Dis Suppl 139:54-56

4. Passali D, Ferri L, Becchini G, Passali C, Bellussi L (1999) Alterations of nasal mucociliary transport in patients with hypertrophy of the inferior turbinates, deviations of the nasal septum and chronic sinusitis. Eur Arch Otorhinolaryngol 256:335-337

5. Juhani N (1996) Asymmetry in the nasal mucociliary transport rate. Laryngoscope 106:1424-1428

6. Lindberg S, Rimer T (1994) Method for in vivo measurement of mucociliary activity in the human nose. Ann Otol Rhinol Laryngol 103:558

7. Di Gueda D, Galli J, Calcagni ML, Corina L, Paludetti G, Ottoviani F, De Rossi G (2000) Rhinoscintigraphy: a simple radioisotope technique to study the mucociliary system. Clin Nucl Med 2:127

8. Uslu H, Uslu C, Varoglu E, Demirci M, Seven B (2004) Effects of septoplasty and septal deviation on nasal mucociliary clearance. Int J Clin Pract 58:1108-1111

9. Ulusoy B, Arbag H, Sari O, Yondemli F (2007) Evaluation of the effects of nasal septal deviation and its surgery on nasal mucociliary clearance in both nasal cavities. Am J Rhinol 21:180-183

10. Boyce J, Eccles R (2006) Do chronic changes in nasal airflow have any physiological or pathological effect on the nose and paranasal sinuses? A systematic review. Clin Otolaryngol 31:15-19

11. Jang YC, Myong NH, Park KH, Koo TW, Kim HG (2002) Mucociliary transport and histologic characteristics of the mucosa of deviated nasal septum. Arch Otolaryngol Head Neck Surg 128:421-424

12. Schwentner I, Dejakum K, Schmutzhard J, Deibl M, Sprinzl GM (2006) Does nasal septal surgery improve quality of life? Acta Otolaryngol 126:752-757

13. Becker SS, Dobratz EJ, Stowell N et al (2008) Revision septoplasty: review of sources of persistent nasal obstruction. Am J Rhinol 22:440-444

14. Elahi MM, Frenkiel S, Fageeh N (1997) Paraseptal structural changes and chronic sinus disease in relation to the deviated septum. J Otolaryngol 26:236-240 
15. Tawakir K, Yılmaz T, Sunucu S, Ergin T, Keith AB (2006) Scanning electron microscopy of ciliae and saccharin test for ciliary function in septal deviation. Laryngoscope 116:586-590

16. Brondeel L, Sonstabo R, Clement P et al (1983) Value of Tc-99m particle test, the saccharine test in mucociliary examinations. Rhinology 21:135

17. Kao CH, Jiang RS, Wang SJ, Yeh SH (1994) Influence of age, gender, and ethnicity on nasal mucociliary clearance function. Clin Nucl Med 19:813-816

18. Passali D, Bianchi Ciampoli M (1985) Normal values of mucociliary transport time in young subjects. Int J Pediatr Otolaryngol 9:151-156

19. Cohen NA (2006) Sinonasal mucociliary clearance in health and disease. Ann Otol Rhinol Laryngol Suppl 196:20-26

20. Stanley PJ, Wilson R, Greenstone MA, MacWilliam L, Cole PJ (1986) Effect of cigarette smoking on nasal mucociliary clearance and ciliary beat frequency. Thorax 41:519-523
21. Cingi C, Altin F, Cakli H, Entok E, Gurbuz K, Cingi E (2005) Scintigrafic evaluation of nasal mucociliary activity in unilateral chronic otitis media. J Laryngol Otol 119:443-447

22. Sun SS, Hsieh JF, Tsai SC, Ho YJ, Kao CH (2002) Evaluation of nasal mucociliary clearance function in allergic rhinitis patients with technetium 99m-labelled macroagregated albumin rhinoscintigraphy. Ann Otol Rhinol Laryngol 111:77-79

23. Boek WM, Graamans K, Natzijl HR, Peter P, Huizing EH (2002) Nasal mucociliary transport: new evidence for a key role of ciliary beat frequency. Laryngoscope 112:570-573

24. Ohashi Y, Nakai Y, Ikeoka H, Furuya H (1991) Regeneration of nasal mucosa following mechanical injury. Acta Otolaryngol Suppl 486:193-201 